Check for updates

Cite this: Phys. Chem. Chem. Phys., 2018, 20, 27214

Received 18th September 2018 Accepted 17th October 2018

DOI: $10.1039 / c 8 c p 05884 a$

rsc.li/pccp

\section{Tuning phase transitions of aqueous protein solutions by multivalent cations $\dagger$}

\author{
Olga Matsarskaia, iD a Felix Roosen-Runge, (iD *b Gudrun Lotze, (iD c \\ Johannes Möller, ${ }^{c}$ Alessandro Mariani, (iD ' Fajun Zhang (iD ${ }^{\text {a }}$ and \\ Frank Schreiber (iD *a
}

\begin{abstract}
In the presence of trivalent cations, negatively charged globular proteins show a rich phase behaviour including reentrant condensation, crystallisation, clustering and lower critical solution temperature metastable liquid-liquid phase separation (LCST-LLPS). Here, we present a systematic study on how different multivalent cations can be employed to tune the interactions and the associated phase behaviour of proteins. We focus our investigations on the protein bovine serum albumin (BSA) in the presence of $\mathrm{HoCl}_{3}, \mathrm{LaCl}_{3}$ and $\mathrm{YCl}_{3}$. Using UV-Vis spectroscopy and small-angle X-ray scattering (SAXS), we find that the interprotein attraction induced by $\mathrm{Ho}^{3+}$ is very strong, while the one induced by $\mathrm{La}^{3+}$ is comparatively weak when comparing the data to $\mathrm{BSA}-\mathrm{Y}^{3+}$ systems based on our previous work. Using zeta potential and isothermal titration calorimetry (ITC) measurements, we establish different binding affinities of cations to BSA with $\mathrm{Ho}^{3+}$ having the highest one. We propose that a combination of different cation features such as radius, polarisability and in particular hydration effects determine the proteinprotein interaction induced by these cations. Our findings imply that subtle differences in cation properties can be a sensitive tool to fine-tune protein-protein interactions and phase behaviour in solution.
\end{abstract}

\section{Introduction}

A thorough understanding of phase transitions in protein solutions is of utmost importance for the design and stabilisation of protein-based therapeutics, ${ }^{1,2}$ disentangling cell-signalling processes, ${ }^{3}$ finding treatment options for protein condensation diseases ${ }^{4}$ as well as rationally manipulating pathways of protein crystallisation. ${ }^{5}$ The heterogeneous charge distribution and intricate interactions with their environment - the latter can additionally be influenced by various parameters including temperature, pH and pressure - make proteins highly complex molecules. In an attempt to better understand and investigate proteins and their interactions with their surroundings, it is thus helpful to make use of simplified physical models.

In this context, the framework of colloid theory with corresponding model interaction potentials provides a successful approach. An important insight from colloid science describes

\footnotetext{
${ }^{a}$ Institut für Angewandte Physik, Universität Tübingen, Auf der Morgenstelle 10, 72076 Tübingen, Germany. E-mail: frank.schreiber@uni-tuebingen.de; Fax: +497071 295110; Tel: +4970712978663

${ }^{b}$ Division of Physical Chemistry, Lund University, Lund, Sweden.

E-mail: felix.roosen-runge@fkem1.lu.se

${ }^{c}$ ESRF, Grenoble, France

$\dagger$ Electronic supplementary information (ESI) available: Calculation of effective protein surface charge from zeta potentials and derivation of zeta potential fitting equation. See DOI: 10.1039/c8cp05884a
}

the influence of the interaction range between particles on their phase behaviour. Specifically, interparticle attraction on a range smaller than the particle diameter is reflected in a metastable liquid-liquid coexistence region which shifts below the gas-crystal line. ${ }^{6-9}$ This liquid-liquid coexistence, also referred to as liquidliquid phase separation (LLPS), can be considered analogous to the liquid-gas transition in the van der Waals gas. ${ }^{10}$ The experimental evidence for this phenomenon in colloidal systems, which also laid the foundation for its subsequent theoretical rationalisation by Gast et al. ${ }^{11}$ was provided by Sperry and co-workers ${ }^{12}$ in a latex-polymer system with depletion attraction.

Importantly, such phenomena can also be observed in protein solutions. One of the earliest observations of LLPS in a protein system was documented by Tanaka et al. for an aqueous lysozyme-NaCl mixture. ${ }^{13}$ Since then, many more examples of LLPS in different protein solutions have been described. Examples include crystallins, ${ }^{14-17}$ different types of hemoglobin, ${ }^{18-20}$ lysozyme, ${ }^{8,21}$ polypeptides derived from elastin ${ }^{22}$ as well as cellular structures. ${ }^{23}$

Under physiological conditions, proteins and their interactions are influenced by cations such as $\mathrm{Na}^{+}, \mathrm{K}^{+}, \mathrm{Ca}^{2+}, \mathrm{Mg}^{2+}$ or $\mathrm{Zn}^{2+} \cdot{ }^{24}$ Moreover, many proteins, notably serum albumins, can directly bind and transport cations. ${ }^{25}$ In addition to these physiologically occuring cation species, the interactions of proteins with less common cations such as lanthanides (Ln) are of fundamental interest in toxicology, ${ }^{26,27}$ the onset and development of 
neurodegenereative diseases, ${ }^{28,29}$ bacterial metabolism, ${ }^{30}$ tumour treatment ${ }^{31,32}$ as well as spectroscopic ${ }^{33}$ and diagnostic methods. ${ }^{34-36}$ Cation-specific effects are not limited to proteins, but similarly occur in soft matter systems. For example, a recent study by $\mathrm{Yu}$ et $a .^{37}$ showed a strong decrease in polyelectrolyte brush lubricity upon the addition of multivalent cations such as $\mathrm{Y}^{3+}$.

Throughout the past years, our group has successfully established a rich phase behaviour induced in negatively charged globular proteins by trivalent salts such as $\mathrm{YCl}_{3}$. It has been found that $\mathrm{Y}^{3+}$ cations introduce a short-range attraction between the protein molecules by forming cation bridges between negatively charged residues of protein molecules, ${ }^{5}$ leading to a variety of phenomena including crystallisation, ${ }^{5,38,39}$ cluster formation, ${ }^{39}$ reentrant condensation, ${ }^{88,40,41}$ and metastable LLPS $^{39}$ with a lower critical solution temperature (LCST-LLPS). ${ }^{42-44}$

A representative salt-protein concentration $\left(c_{\mathrm{s}}-c_{\mathrm{p}}\right)$ phase diagram of a negatively charged globular protein in the presence of a trivalent salt describing our experimental systems is shown in Fig. 1. The dashed arrow in the right part shows the phase transitions at constant $c_{\mathrm{p}}$ upon increasing $c_{\mathrm{s}}$. In regime I, at low $c_{\mathrm{s}}$, few cations bind to protein molecules. The overall protein surface charge is negative (left part of Fig. 1) and the net interactions are thus repulsive. An increasing $c_{\mathrm{s}}$ leads to a weakened protein surface charge and a subsequent condensation of the protein solution. This area of the phase diagram is referred to as regime II and is separated from regime I by a critical salt concentration $c^{*}$. Under appropriate conditions, a sample located in a certain region of the phase diagram (orange sphere on yellow ellipsoid) can undergo liquid-liquid phase separation into a protein-rich and a protein-poor phase (brown and yellow spheres on the high- and low- $c_{\mathrm{p}}$ edges of the yellow ellipsoid, respectively), which is due to a short-range interprotein attraction induced by cation bridging. ${ }^{38}$ An even further increase of $c_{\mathrm{s}}$ leads to a charge inversion of the protein surface due to an extensive binding of cations upon crossing a second critical salt concentration $c^{* *}$. These experimental findings can be rationalised from a theoretical point of view in the framework of an ion-activated patchy particle model ${ }^{45}$ which combines a hard-sphere repulsion of the proteins and a square-well

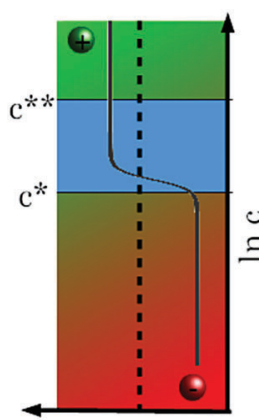

Net charge

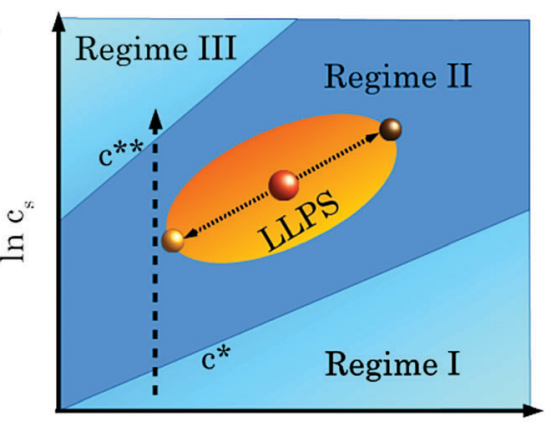

$\ln c_{p}$
Fig. 1 Phase diagram showing regimes I, II and III, reentrant condensation and LLPS. See text for details. attraction induced by cations binding to patches (negatively charged amino acid residues) on the protein surface. This mechanism features similarities to cation-mediated condensation of DNA ${ }^{46,47}$ Interestingly, molecular dynamics and Monte Carlo studies by Pasquier et $a l .{ }^{48}$ show an anomalous development of the protein-protein potential of mean force with increasing salt concentration in a system of human serum albumin (HSA) and $\mathrm{YCl}_{3}$. The results obtained by Pasquier et $a .^{48}$ are in excellent agreement with the different regions of the experimental phase diagram shown in Fig. 1.

Previous studies showed that this phase behaviour also depends on the choice of the salt. We have found that trivalent salts other than $\mathrm{YCl}_{3}$ (such as $\mathrm{FeCl}_{3}$ and $\mathrm{AlCl}_{3}$ ) also induce reentrant condensation. However, we established that as opposed to $\mathrm{YCl}_{3}$, pH effects on the reentrant phase behaviour due to salt hydrolysis are significant in the case of $\mathrm{FeCl}_{3}$ and $\mathrm{AlCl}_{3}{ }^{41}$ Furthermore, we found that for a protein solution with fixed $\mathrm{YCl}_{3}$ concentration, the addition of a monovalent salt could be used to shift the phase boundaries to higher critical concentrations, suggesting a subtle balance of charge repulsion and salt-induced attraction to be essential for the phase behaviour. ${ }^{49}$ The effect of different counterions of lanthanide cations on the phase behaviour of BSA is subject of a recent investigation..$^{50}$

Given that details of the interaction potential have a strong influence on the phase behaviour of colloidal systems, we aim at investigating the influence of cations with different radii and chemical properties $\left(\mathrm{Ho}^{3+}, \mathrm{La}^{3+}\right.$ and $\left.\mathrm{Y}^{3+}\right)$. Note that none of these cations cause strong $\mathrm{pH}$ effects by hydrolysis, and therefore the changes observed are due to different effective interactions due to subtle differences in the cation properties. Our main interest consists in fine-tuning and controlling the phase behaviour of protein solutions using different cations.

In the present work, we first describe macroscopic observations which evidence that different trivalent cations lead to remarkably strong differences in the phase behaviour of bovine serum albumin (BSA). Determining transition temperatures of different protein-cation mixtures by UV-Vis spectroscopy, we observe a strong interprotein attraction induced by $\mathrm{Ho}^{3+}$ in BSA solutions, whereas these attractions are weaker in the presence of $\mathrm{La}^{3+}$. Systems consisting of BSA and $\mathrm{Y}^{3+}$ are used as a reference. Reduced second virial coefficient values $\left(B_{2} / B_{2}^{\mathrm{HS}}\right)$ obtained from small-angle X-ray scattering (SAXS) confirm this conclusion. In addition to cation-induced protein interactions, we study cation binding to BSA by zeta potential measurements and isothermal titration calorimetry (ITC) to obtain a comprehensive thermodynamic characterisation of cation-protein interactions.

\section{Materials}

Bovine serum albumin (BSA, product no. A7906), $\mathrm{YCl}_{3}, \mathrm{HoCl}_{3}$ and $\mathrm{LaCl}_{3}$ were purchased from Sigma Aldrich (Taufkirchen, Germany, now Merck, Darmstadt, Germany) and used without further purification. Protein and salt powders were dissolved in 
ultrapure degassed water (18.2 M $\Omega$, Merck Millipore, Darmstadt, Germany). The exact protein concentration was determined using UV-Vis spectroscopy (Cary 50 UV-Vis spectrometer, Varian Inc., now Agilent Technologies, California, USA; absorbance at $280 \mathrm{~nm}$ ). Samples were subsequently prepared by mixing appropriate volumes of aqueous protein and salt stock solutions.

\section{Experimental methods}

\subsection{Isothermal coexistence phase diagrams}

$c_{\mathrm{s}}-c_{\mathrm{p}}$ phase diagrams were determined at room temperature for $80 \mathrm{mg} \mathrm{ml}^{-1}(1.2 \mathrm{mM})$ BSA and increasing concentrations of $\mathrm{HoCl}_{3}$, $\mathrm{LaCl}_{3}$ and $\mathrm{YCl}_{3}$. The dilute phases were studied by visual inspection and light microscopy. Samples with dilute phases that were homogeneous under the microscope but appeared turbid upon visual inspection were classified as "turbid". Where liquid-liquid phase separation was visible under the microscope, the samples were labelled as "LLPS". In the absence of any inhomogeneity, samples were classified as "clear".

\subsection{T-Dependent UV-Vis spectroscopy}

All of the BSA-trivalent cation systems studied here show a LCST-LLPS-type behaviour. To elucidate the differences in protein-protein interactions induced by the different cations, cation mixtures were used. In order to determine the respective transition temperatures $T_{\text {trans }}$ from homogeneous to phaseseparated states of the BSA-cation mixtures, temperaturedependent UV scans were performed using a Cary 50 UV-Vis spectrometer (Varian Inc., now Agilent Technologies, California, USA) connected to a water bath (Haake A 10B, Thermo Fisher Scientific, Schwerte, Germany). Samples were then subjected to temperature scans at a rate of $0.1 \mathrm{~K} \mathrm{~min}^{-1}$ while their absorbance was monitored over a wavelength range from 400 to $800 \mathrm{~nm}$. The intensity values of the spectra obtained were summed and divided by the respective number of data points. $T_{\text {trans }}$ was determined from the maximum of the first derivatives with respect to temperature of the respective curves.

\subsection{Zeta potential measurements}

Zeta potentials were measured by electrophoretic light scattering (ELS) using a Nano Zetasizer (Malvern Instruments, Malvern, United Kingdom). Samples containing $1 \mathrm{mg} \mathrm{ml}^{-1}(15 \mu \mathrm{M})$ BSA and increasing salt concentrations $(0.1,0.3,0.5,0.7$ and $1 \mathrm{mM}$ of $\mathrm{HoCl}_{3}, \mathrm{YCl}_{3}$ or $\mathrm{LaCl}_{3}$ ) were prepared shortly before the measurements. The low BSA concentration was chosen to avoid phase separation of the samples. Every sample was measured at 5 different temperatures, with $10 \mathrm{~min}$ of equilibration time before each measurement. The $\zeta$ potential values were subsequently converted into effective surface charge values $Q$ in units of elementary charge $e$ as explained in the ESI. $\dagger$

\subsection{Isothermal titration calorimetry (ITC)}

ITC measurements were performed using a MicroCal iTC200 (Malvern Instruments, formerly GE Healthcare). Salt solutions with concentrations of $800 \mu \mathrm{M}$ or $3 \mathrm{mM}$ were titrated into
$1 \mathrm{mg} \mathrm{m} \mathrm{m}^{-1}(15 \mu \mathrm{M})$ BSA solutions in $0.5 \mu \mathrm{l}$ steps with a duration of $1 \mathrm{~s}$ each. A preliminary titration step of $0.2 \mu \mathrm{l}$ with a duration of $0.5 \mathrm{~s}$ was used for equilibration. In the case of the titrations performed with $3 \mathrm{mM}$ salt solution, the durations of these steps were 0.4 and $1 \mathrm{~s}$, respectively. In order to correct for the heat of dilution of the salt, a background measurement was performed by titrating the $800 \mu \mathrm{M}$ or $3 \mathrm{mM}$ salt solutions into water. The background measurements were subtracted from the saltprotein measurements. For each measurement, 60 injections were performed in total. The time interval between each injection was $90 \mathrm{~s}$ with a filter period of $5 \mathrm{~s}$. For titrations with $3 \mathrm{mM}$ salt solutions, these time intervals were 180 and $2.5 \mathrm{~s}$, respectively. The stirring speed of the syringe was $750 \mathrm{rpm}$ and the reference power was set to $1.3 \mu \mathrm{cal} \mathrm{s}^{-1}$. All data sets were taken at $24{ }^{\circ} \mathrm{C}$.

\subsection{Small-angle X-ray scattering (SAXS)}

SAXS measurements were performed at beamline ID02 (ESRF, Grenoble, France) at a sample-detector distance of $2 \mathrm{~m}$ and an energy of 12.46 or $16 \mathrm{keV}(\lambda=0.8-0.9 \AA)$. The scattered intensity was recorded using a Rayonix MX160 or a FReLoN Kodak CCD detector, covering a $q$ range within 0.01 to $5 \mathrm{~nm}^{-1}$.

Samples containing 80 or $85 \mathrm{mg} \mathrm{ml}^{-1}(=1.2$ or $1.3 \mathrm{mM})$ BSA and increasing (0-50 mM) concentrations of $\mathrm{HoCl}_{3}, \mathrm{LaCl}_{3}$ or $\mathrm{YCl}_{3}$ were prepared at room temperature $\left(\mathrm{ca} .21{ }^{\circ} \mathrm{C}\right)$ and centrifuged for $5 \mathrm{~min}$ at $9500 \mathrm{rcf}$ to facilitate phase separation for those samples located in the LLPS region of their respective phase diagrams. Samples were loaded into a flow-through capillary and measured at a constant temperature of $20{ }^{\circ} \mathrm{C}$ controlled by a Peltier element connected to the flow cell. In the case of phase-separated samples, the dilute phases were measured. Per sample, 5-10 acquisitions were performed with an exposure time of $0.05-0.1 \mathrm{~s}$. The data were calibrated to absolute intensity using water as a reference. ${ }^{51}$ Data were averaged and background-corrected using either water or pure salt solutions with appropriate concentrations.

In a SAXS experiment, the scattering intensity $I(q)$ is measured as a function of momentum transfer $q=\frac{4 \pi}{\lambda} \sin (\theta)$ with a scattering angle $2 \theta .^{52}$ It can be expressed as

$$
I(q)=\Phi V_{\text {particle }}(\Delta \rho)^{2} P(q) S(q)
$$

where $V_{\text {particle }}$ represents the volume of a particle (i.e. protein) in question, $\Phi$ the volume fraction of particles in the sample and $\Delta \rho$ the scattering contrast between solvent and particles. $P(q)$, the form factor of the particles, represents the Fourier transform of their respective electron densities.

In systems with sufficiently high particle concentrations where intermolecular interactions cannot be neglected, the latter are accounted for by the structure factor

$$
S(q)=1+4 \pi \rho \int_{0}^{\infty} \mathrm{d} r r^{2} h(r) \frac{\sin (q r)}{q r}
$$

where $\rho=N / V$ and $h(r)=g(r)-1$ is the total correlation function. ${ }^{53}$ 
Importantly, the structure factor at $q \rightarrow 0$ is proportional to the osmotic compressibility $(\partial \Pi / \partial c)^{-1}$ of the system in question $^{54,55}$ which can be expanded into a series of virial coefficients $A_{n}:^{54,56}$

$$
S(q \rightarrow 0)=\frac{R T}{M}\left(\frac{\partial \Pi}{\partial c}\right)^{-1}=\frac{1}{1+2 M A_{2} c+\ldots}
$$

where $R=8.314 \mathrm{~J} \mathrm{~K}^{-1} \mathrm{~mol}^{-1}$ is the ideal gas constant, $T$ is the temperature and $M$ is the molecular weight of the particles investigated. The second virial coefficient $B_{2}$ is related to $A_{2} v_{i a}{ }^{57}$

$$
B_{2}=A_{2} \cdot \frac{M^{2}}{N_{\mathrm{A}}}
$$

where $N_{\mathrm{A}}$ is Avogadro's constant $\left(6.022 \times 10^{23} \mathrm{~mol}^{-1}\right)$. In this study, the normalised second virial coefficient $B_{2} / B_{2}^{\mathrm{HS}}$ (with $B_{2}^{\mathrm{HS}}=2 \pi \sigma^{3} / 3$ being the second virial coefficient of a system consisting of hard spheres with diameter $\sigma^{58}$ ) is calculated from the SAXS profiles in order to characterise the overall nature of their interactions.

For $c_{\mathrm{s}}=0-3 \mathrm{mM}$, the form factor was combined with a screened Coulomb (SC) structure factor. ${ }^{59,60}$ The screened Coulomb potential is expressed as

$$
\beta U(x)= \begin{cases}\gamma \mathrm{e}^{-k x} / x & (x>1) \\ \infty & (x \leq 1)\end{cases}
$$

where $x=r / \sigma$ (interparticle distance normalised by particle diameter) and $k=\kappa \sigma$ with $\kappa$ being the Debye screening length. $\beta=\left(k_{\mathrm{B}} T\right)^{-1}$ and $\gamma \mathrm{e}^{-k}=\beta \pi \varepsilon_{0} \varepsilon \sigma \psi_{0}^{2}\left(\varepsilon_{0}\right.$ is the vacuum permittivity, $\varepsilon$ the permittivity of the solvent, $\sigma$ the particle diameter and $\psi_{0}$ the surface potential) represents the potential upon contact of two particles (in this case, proteins).

For $c_{\mathrm{s}} \geq 4 \mathrm{mM}$, a sticky hard sphere structure (SHS) factor was used. ${ }^{61-63}$ The SHS potential is expressed as ${ }^{63}$

$$
U(r)= \begin{cases}\infty, & r \leq \sigma \\ -\varepsilon, & \sigma<r \leq \lambda \sigma \\ 0, & \lambda \sigma<r\end{cases}
$$

where the range of the attractive part of the potential, $R$, is equal to $\lambda-1$. The stickiness parameter $\tau$ is defined $v i a^{62,63}$

$$
\tau^{-1}=4\left[\exp \left(-\varepsilon / k_{\mathrm{B}} T\right)-1\right]\left[(a-\sigma)^{3}-1\right]
$$

where $a=\sigma+\Delta$ and $\Delta$ is the attractive well width. ${ }^{62}$

From $\tau$, the reduced second virial coefficient is obtained via $B_{2} / B_{2}^{\mathrm{HS}}=1-1 /(4 \tau) .{ }^{58}$ The fitting routine using the software Igor $\mathrm{PRO}^{64}$ employed here has been described in detail elsewhere (see ref. 38, 43 and 65).

\section{Results}

\subsection{Macroscopic properties of phase-separated samples}

Fig. 2 shows a series of samples consisting of aqueous solutions of $80 \mathrm{mg} \mathrm{ml}^{-1}(=1.2 \mathrm{mM})$ BSA and the same concentration $(14 \mathrm{mM})$ of different trivalent salts prepared at $21{ }^{\circ} \mathrm{C}$. In the sample containing $\mathrm{YCl}_{3}$, a moderate amount of a clear,

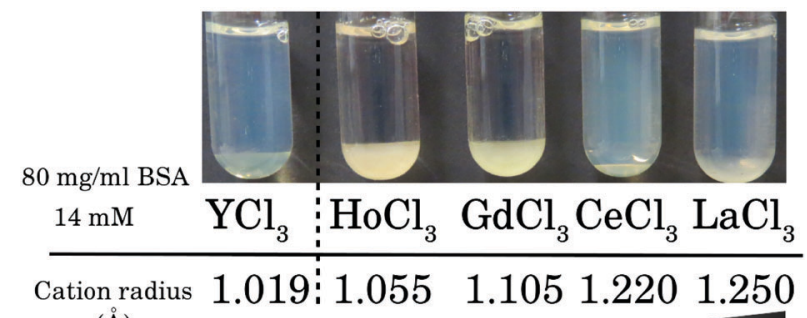

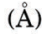

Fig. 2 Comparison of dense phases of liquid-liquid phase separated samples containing $80 \mathrm{mg} \mathrm{ml}^{-1}$ BSA and different trivalent salts. The protein concentration $\left(c_{\mathrm{p}}\right)$ is $80 \mathrm{mg} \mathrm{ml}^{-1}$, the salt concentration $\left(C_{\mathrm{s}}\right)$ is $14 \mathrm{mM}$ in every sample. All samples are located in the LLPS region of regime II of their respective $c_{s}-c_{p}$ phase diagrams. Note that the dense phases obtained in the presence of $\mathrm{Ho}^{3+}$ and $\mathrm{Gd}^{3+}$ may correspond to an arrested state (see text for details). The cationic radii of the lanthanides are obtained from ref. 66 and that of $Y^{3+}$ from ref. 67. The dashed vertical line between $\mathrm{YCl}_{3}$ and $\mathrm{HoCl}_{3}$ indicates that $\mathrm{YCl}_{3}$ is used as a reference system.

yellowish, dense liquid phase is observed, consistent with earlier observations. ${ }^{5,40,42}$ The samples made with $\mathrm{HoCl}_{3}$ and $\mathrm{GdCl}_{3}$ form a substantial amount of dense phase; the dense phases are opaque, but still flow slowly. Using $\mathrm{CeCl}_{3}$ leads to a strong decrease of the amount of dense phase, which in this case is transparent. When $\mathrm{LaCl}_{3}$ is used, no dense phase is formed at $21{ }^{\circ} \mathrm{C}$ (see also ref. 43). The diffuse turbid region at the bottom of this sample and in the dilute phases of the samples prepared with $\mathrm{YCl}_{3}$ and $\mathrm{CeCl}_{3}$ is presumably due to cluster formation in regime II. This macroscopic observation thus indicates differences in protein-protein and protein-salt interactions induced by the different lanthanide salts used. Based on Fig. 2, the strongest protein-protein interactions are expected for $\mathrm{HoCl}_{3}$ and the weakest ones for $\mathrm{LaCl}_{3}$. We therefore focused our studies on $\mathrm{HoCl}_{3}$ and $\mathrm{LaCl}_{3}$, using $\mathrm{YCl}_{3}$ as a reference system based on extensive previous work. ${ }^{5,38-40,68}$

\subsection{Isothermal coexistence $c_{\mathrm{s}}-c_{\mathrm{p}}$ phase diagram}

As a first step towards a more quantitative description of the phase behaviours of our systems, phase diagrams were established for BSA in the presence of $\mathrm{YCl}_{3}, \mathrm{LaCl}_{3}$ and $\mathrm{HoCl}_{3}$. Homogeneous samples with salt concentrations below $c^{*}$ and beyond $c^{* *}$ as well as liquid-liquid coexistence diagrams of phase-separated samples in regime II are shown in Fig. 3.

Fig. 3 illustrates the differences in the isothermal phase behaviour of BSA induced by the three different salts studied here. The most striking feature is the complete lack of LLPS at room temperature when $\mathrm{LaCl}_{3}$ is used. ${ }^{43}$ Using $\mathrm{HoCl}_{3}$, however, leads to a rather broad region of LLPS, larger still than the one induced by $\mathrm{YCl}_{3}$. The $\mathrm{BSA}-\mathrm{HoCl}_{3}$ one shows more aggregation than the $\mathrm{BSA}^{-} \mathrm{YCl}_{3}$ one. A detailed characterisation of the properties of these dense phases is beyond the scope of the present publication. Nevertheless, the presence of aggregates suggests that the dense phases of the $\mathrm{BSA}-\mathrm{Ho}^{3+}$ system may be in an arrested state caused by a stronger intermolecular attraction, as observed for other protein systems. ${ }^{21}$ This interpretation is further supported by the observation that dense $\mathrm{BSA}-\mathrm{Ho}^{3+}$ 


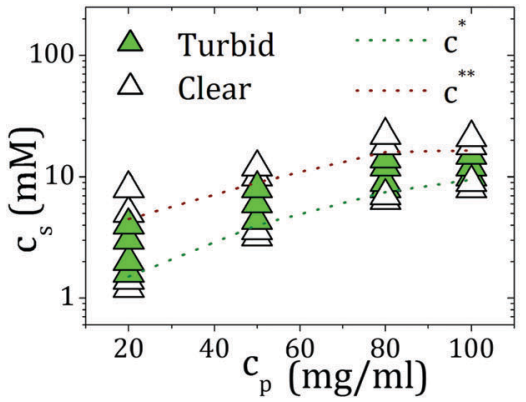

(a) $\mathrm{BSA}+\mathrm{LaCl}_{3}$.

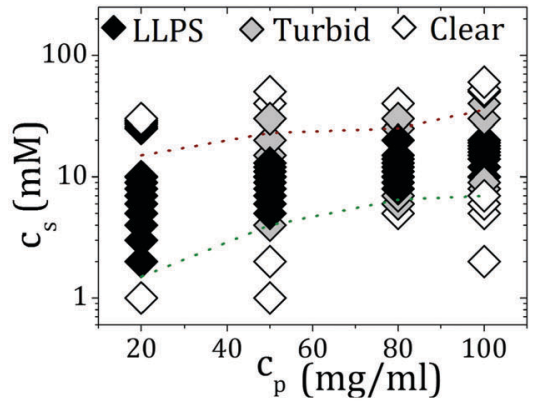

(b) $\mathrm{BSA}+\mathrm{YCl}_{3}$.

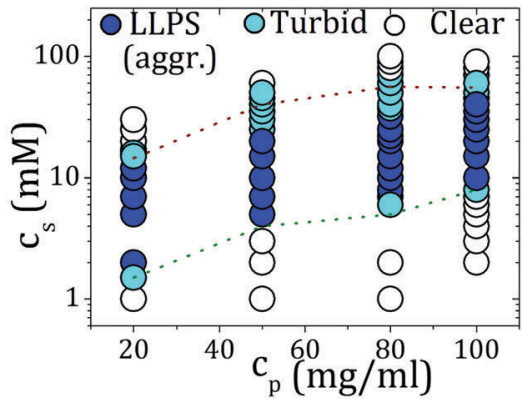

(c) $\mathrm{BSA}+\mathrm{HoCl}_{3}$.

Fig. 3 Isothermal phase diagrams of $\mathrm{BSA}$ in the presence of $\mathrm{LaCl}_{3}, \mathrm{HoCl}_{3}$ and $\mathrm{YCl}_{3}$. Data in (a) are replotted based on ref. 43 . In the presence of $\mathrm{HoCl}_{3}$, the dense phases formed feature network-like structures which may indicate aggregation. Nevertheless, these samples still show LCST behaviour and are therefore classified as showing both aggregation and LLPS.

(and BSA- $\mathrm{Gd}^{3+}$ ) phases appear turbid after preparation, but can mature into clear dense phases after several weeks.

\subsection{Temperature-dependent UV spectroscopy}

As an alternative route to investigate the effect of different cations on the macroscopic phase behaviour of our experimental systems, we systematically determined the cloud temperature $T_{\text {trans }}$ for BSA in the presence of cation mixtures. Fig. 4 shows a typical data set obtained for a constant BSA concentration of $80 \mathrm{mg} \mathrm{ml}^{-1}(1.2 \mathrm{mM})$. The total salt concentration was also kept constant at $10 \mathrm{mM}$ while increasing the $\mathrm{HoCl}_{3}$ fraction and simultaneously decreasing that of $\mathrm{LaCl}_{3}$. Similar scans were also performed using different $\mathrm{YCl}_{3} / \mathrm{LaCl}_{3}$ and $\mathrm{YCl}_{3} / \mathrm{HoCl}_{3}$ ratio combinations. The transition temperature $T_{\text {trans }}$ of each system was determined as the maximum of the first derivatives with respect to temperature of the respective integrated absorbance curves.

In order to quantify the influence of different cations on $T_{\text {trans }}$ of the different cation mixtures, the differences in $T_{\text {trans }}$ values $\left(\Delta T_{\text {trans }}\right)$ between different mixtures and samples containing $100 \% \mathrm{YCl}_{3}$ (the $T_{\text {trans }}$ of which is $30.6{ }^{\circ} \mathrm{C}$ ) were calculated (Fig. 5). As can be seen from the rightmost part

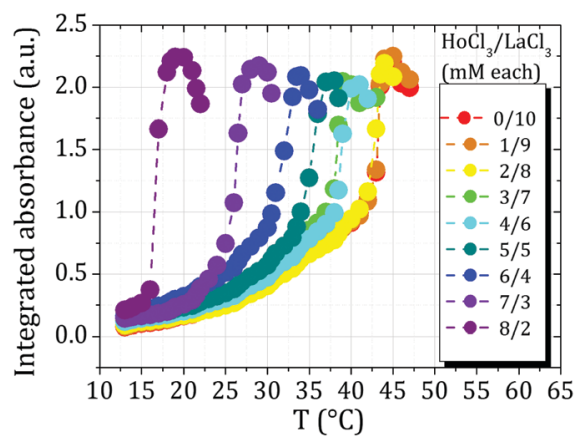

Fig. 4 Typical series of $T$-dependent absorbance measurements (raw data) of samples containing a constant $c_{\mathrm{p}}$ of $80 \mathrm{mg} \mathrm{m}^{-1}(1.2 \mathrm{mM})$ BSA and a constant total ionic strength of $10 \mathrm{mM}$ consisting of different salt ratios (here: $\mathrm{HoCl}_{3} \& \mathrm{LaCl}_{3}$ ). Similar series were also recorded for mixtures of $\mathrm{HoCl}_{3} \& \mathrm{YCl}_{3}$ as well as $\mathrm{YCl}_{3}$ and $\mathrm{LaCl}_{3}$. $T_{\text {trans }}$ values of all samples were compared to a sample with $10 \mathrm{mM}$ pure $\mathrm{YCl}_{3}$ (Fig. 5).
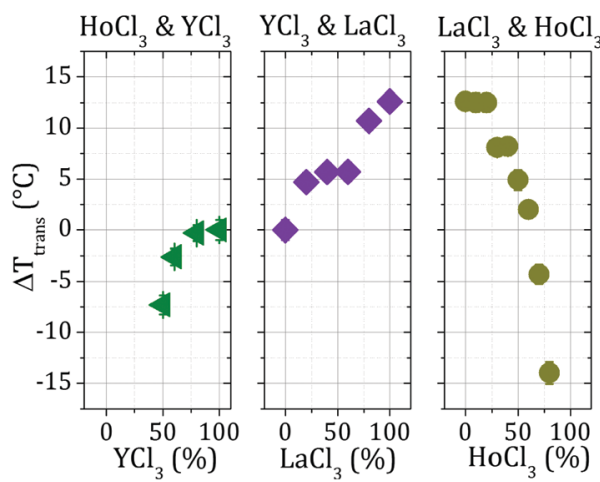

Fig. 5 Difference between $T_{\text {trans }}$ values determined for each sample consisting of BSA and a cation mixture and $T_{\text {trans }}$ of a sample containing $80 \mathrm{mg} \mathrm{ml}^{-1} \mathrm{BSA}$ and $10 \mathrm{mM}$ pure $\mathrm{YCl}_{3}$. Where not visible, error bars are smaller than the data symbols.

$\left(\mathrm{HoCl}_{3} / \mathrm{LaCl}_{3}\right.$ mixtures), the strongest $\Delta T_{\text {trans }}\left(-15{ }^{\circ} \mathrm{C}\right)$ is obtained in a mixture of $20 \% \mathrm{LaCl}_{3}$ and $80 \% \mathrm{HoCl}_{3}$. In other words, with higher fractions of $\mathrm{HoCl}_{3}$, the samples phaseseparate already at lower $T$. This is also the lowest overall $\Delta T_{\text {trans }}$ observed amongst all mixtures investigated and supports the hypothesis that $\mathrm{Ho}^{3+}$ cations induce the strongest interprotein attraction of all cations studied here. This conclusion is also reflected in the fact that samples containing $\mathrm{HoCl}_{3}$ percentages higher than $80 \%$ already phase-separate at $12{ }^{\circ} \mathrm{C}$, the initial equilibration temperature for the measurements presented here. Due to this behaviour, no measurements of BSA- $\mathrm{HoCl}_{3} / \mathrm{LaCl}_{3}$ samples containing more than $80 \% \mathrm{HoCl}_{3}$ could be performed. When mixtures of $\mathrm{YCl}_{3}$ and $\mathrm{HoCl}_{3}$ (leftmost part of Fig. 5) are considered, any sample with a $\mathrm{HoCl}_{3} / \mathrm{YCl}_{3}$ ratio higher than 50/50 also phase-separates already at $12{ }^{\circ} \mathrm{C}$. The higher the fraction of $\mathrm{HoCl}_{3}$, the higher the $T_{\text {trans }}$ difference to a sample containing only $\mathrm{YCl}_{3}$. Again, this indicates a strong interprotein attraction induced by $\mathrm{Ho}^{3+}$.

In the case of $\mathrm{YCl}_{3} / \mathrm{LaCl}_{3}$ mixtures (central part of Fig. 5), the highest $\Delta T_{\text {trans }}$ is obtained with the highest $\mathrm{LaCl}_{3}$ concentration. This implies that addition of $\mathrm{LaCl}_{3}$ shifts $T_{\text {trans }}$ towards higher values, confirming that $\mathrm{Y}^{3+}$ cations induce a stronger interprotein attraction than $\mathrm{La}^{3+}$ cations. Based on these 
measurements, the cations can be ranked according to the order of increasing cation-induced protein-protein interaction strengths as $\mathrm{La}^{3+}<\mathrm{Y}^{3+}<\mathrm{Ho}^{3+}$.

\subsection{Effective interactions characterised by small-angle X-ray scattering}

Small-angle X-ray scattering (SAXS) was performed in order to characterise the influence that the different cations investigated have on the protein-protein interactions of BSA. Backgroundcorrected SAXS data obtained for BSA in the presence of an increasing $\mathrm{HoCl}_{3}$ concentration are shown in Fig. 6 .

Fig. 6 shows that the intensity at low $q, I(0)$, increases and decreases in an alternating fashion. The intensity $I(0)$ at low $q$ was used to qualitatively estimate the strength of the interactions in the systems investigated (Fig. 7).

Fig. 7 shows three $c_{\mathrm{s}} / c_{\mathrm{p}}$ regimes with consistent results: first, for $c_{\mathrm{s}} / c_{\mathrm{p}}<7,1 / I(0)$ behaves comparably for all cations, with a slightly lower $1 / I(0)$ for $\mathrm{Ho}^{3+}$. For $c_{\mathrm{s}} / c_{\mathrm{p}}$ in the range from 7 to 22 , the different phase behaviours induced by $\mathrm{Ho}^{3+}, \mathrm{Y}^{3+}$ and $\mathrm{La}^{3+}$ are reflected in the strengths of the respective humps. While no hump is observed for $\mathrm{La}^{3+}$, the humps for $\mathrm{Ho}^{3+}$ and $\mathrm{Y}^{3+}$ are related to the reduced protein concentration in the dilute coexisting phases. As in Fig. 3, the LLPS appears more prominent for $\mathrm{HoCl}_{3}$ (i.e. the density difference between the corresponding dense and dilute phases is larger) than for $\mathrm{YCl}_{3}$, and is absent for $\mathrm{LaCl}_{3}$. Finally, at higher $c_{\mathrm{s}} / c_{\mathrm{p}}(>22), 1 / I(0)$ follows the order $\mathrm{Ho}^{3+}<\mathrm{Y}^{3+}<\mathrm{La}^{3+}$. Together with the trend towards lower $T_{\text {trans }}$ values for samples containing $\mathrm{HoCl}_{3}$ (Fig. 5), all these features indicate an interprotein attraction decreasing in the sequence $\mathrm{HoCl}_{3}>\mathrm{YCl}_{3}>\mathrm{LaCl}_{3}$, consistent with the above UV-Vis absorbance data in Section 4.3.

In order to further quantify the cation-induced proteinprotein interactions, the SAXS curves were treated as follows: for salt concentrations $c_{\mathrm{s}}<6 \mathrm{mM}$, data were fitted using a screened Coulomb (SC) potential structure factor; at higher salt concentrations, a sticky hard sphere (SHS) potential structure factor was used (see model fit in Fig. 6). From the curves fitted with the SHS structure factor, stickiness parameters $\tau$ were extracted and used to calculate the reduced second virial coefficients $\left(B_{2} / B_{2}^{\mathrm{HS}}=1-1 /(4 \tau)^{58}\right)$. Being related to the osmotic compressibility of the system investigated (see Methods section), these values can be used as a means to determine the overall
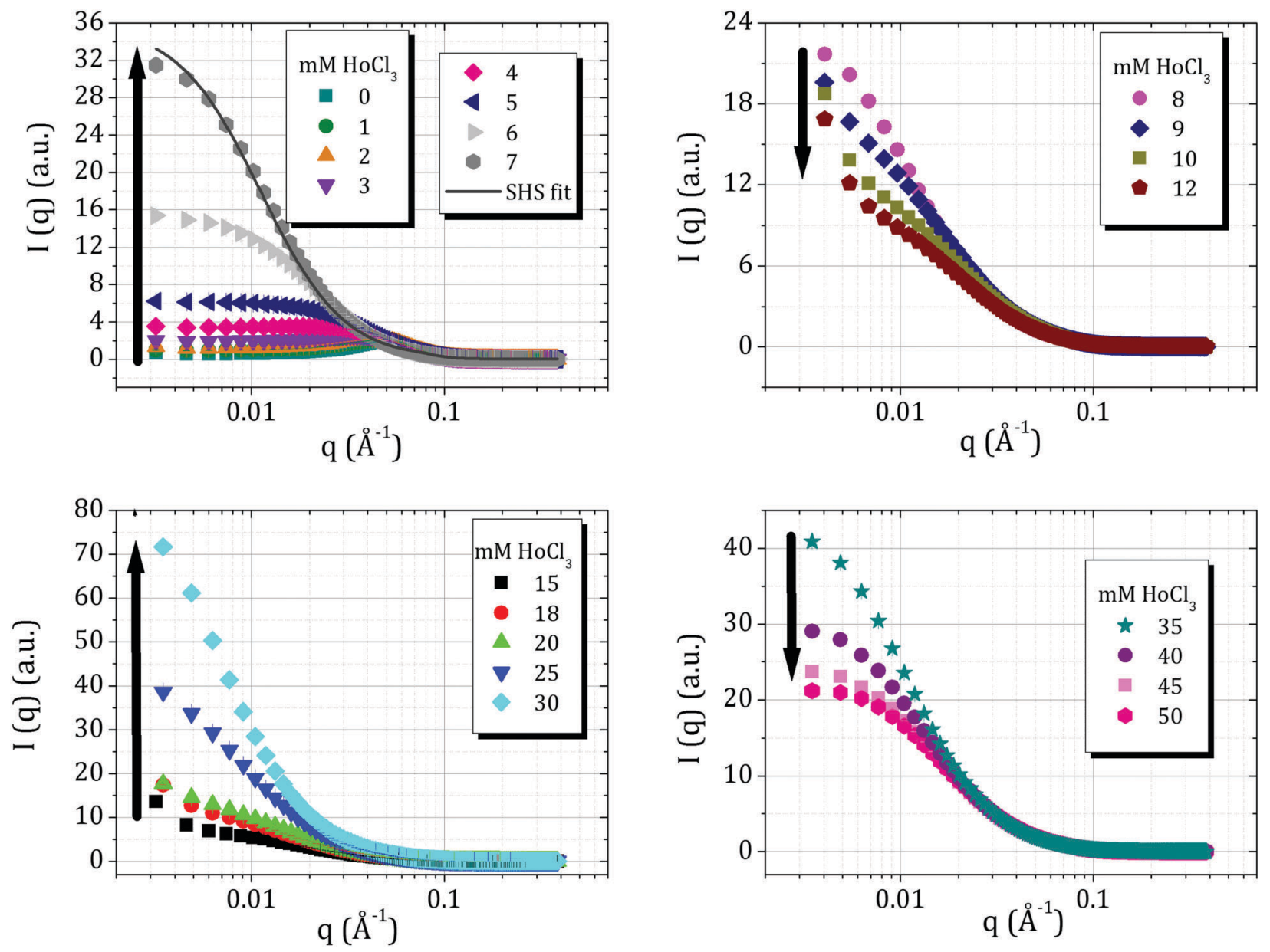

Fig. $6 \mathrm{SAXS}$ profiles of BSA with increasing $\mathrm{HoCl}_{3}$ concentrations. Samples were prepared at a protein concentration of $85 \mathrm{mg} \mathrm{ml}^{-1}$ (1.3 $\mathrm{mM}$ ). In case of phase separation, the SAXS measurements were performed in the dilute phase. Data were normalised to the high $q$ region of a BSA sample without salt $\left(0 \mathrm{mM} \mathrm{HoCl}_{3}\right)$ and only every 5 th data point was plotted for clarity. The dark grey line in the top left part represents an SHS model fit (as also done for the other curves, but omitted for clarity) to the curve obtained in the presence of $7 \mathrm{mM} \mathrm{HoCl}_{3}$. 


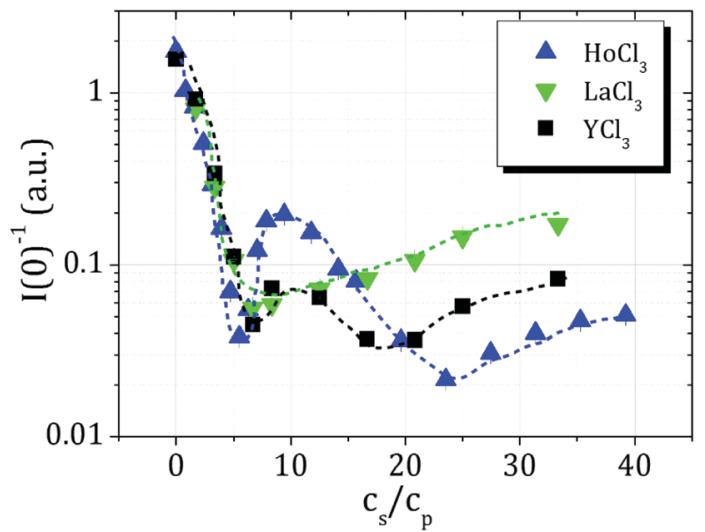

Fig. 7 Inverse $/(0)$ values (determined at $q=0.068 \AA^{-1}$ ) from the respective SAXS curves. Dashed lines represent guides to the eye. $c_{\mathrm{p}}$ is $80 \mathrm{mg} \mathrm{m}^{-1}$ $(=1.2 \mathrm{mM})$ for the $\mathrm{BSA}-\mathrm{YCl}_{3}$ and $\mathrm{BSA}-\mathrm{LaCl}_{3}$ systems and $85 \mathrm{mg} \mathrm{ml}^{-1}$ $(=1.3 \mathrm{mM})$ for the $\mathrm{BSA}-\mathrm{HoCl}_{3}$ system. Where not visible, the error bars are smaller than the symbols.

strength of the interactions of the system in question. In particular, a positive $B_{2} / B_{2}^{\mathrm{HS}}$ indicates overall repulsion whereas negative values indicate net attraction. A value around -1.5 moreover indicates proximity to the critical point of LLPS in colloidal theory. ${ }^{69}$ The $B_{2} / B_{2}^{\mathrm{HS}}$ values obtained for BSA in the presence of $\mathrm{HoCl}_{3}, \mathrm{LaCl}_{3}$ and $\mathrm{YCl}_{3}$ are shown in Fig. 8 as functions of the $c_{\mathrm{s}} / c_{\mathrm{p}}$ ratio.

The $B_{2} / B_{2}^{\mathrm{HS}}$ values obtained for the $\mathrm{BSA}-\mathrm{LaCl}_{3}$ system show that these samples nearly always show net attractive interactions, but, as confirmed by macroscopic experimental data, do not phase-separate under the given conditions. In the $\mathrm{BSA}-\mathrm{YCl}_{3}$ and $\mathrm{BSA}-\mathrm{HoCl}_{3}$ systems, however, the $B_{2} / B_{2}^{\mathrm{HS}}$ values indicate phase separation, as is confirmed from macroscopic observations. The systems containing $\mathrm{YCl}_{3}$ and $\mathrm{HoCl}_{3}$ therefore feature overall stronger attractive interactions.

The $B_{2} / B_{2}^{\mathrm{HS}}$ values of the $\mathrm{BSA}-\mathrm{HoCl}_{3}$ system are overall more negative than those of $\mathrm{YCl}_{3}$ and differ in spite of the rather similar

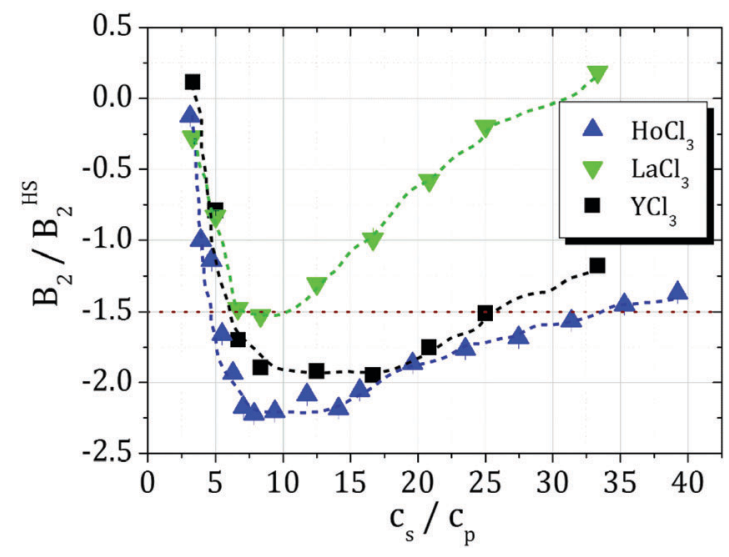

Fig. 8 2nd virial coefficients determined from sticky hard sphere potential fits to background-corrected SAXS data. Dashed lines represent guides to the eye. $c_{p}$ is $80 \mathrm{mg} \mathrm{ml}^{-1}(1.2 \mathrm{mM})$ for the $\mathrm{BSA}-\mathrm{YCl}_{3}$ and $\mathrm{BSA}-\mathrm{LaCl}_{3}$ systems and $85 \mathrm{mg} \mathrm{ml}^{-1}(1.3 \mathrm{mM})$ for the $\mathrm{BSA}-\mathrm{HoCl}_{3}$ system. The dark-red dotted line indicates the critical $B_{2} / B_{2}^{\mathrm{HS}}$ value below which phase separation is expected to occur. ${ }^{69}$ Where not visible, the error bars are smaller than the symbols. cationic radii of $\mathrm{Y}^{3+}$ and $\mathrm{Ho}^{3+}$. Note that the reason for the absence of humps as they are observed in the case of the $1 / I(0)$ data in the $B_{2} / B_{2}^{\mathrm{HS}}$ values is the fact that the density difference between the two phases only manifests itself in the $1 / I(0)$ values. The $B_{2} / B_{2}^{\mathrm{HS}}$ values, however, are equal in coexisting dense and dilute phases (see e.g. ref. 69), meaning that no density-dependent signature like the $1 / I(0)$ hump is visible in the $B_{2} / B_{2}^{\mathrm{HS}}$ plot (Fig. 8).

The macroscopic phase behaviours observed here are linked to a combination of cation-induced interprotein interactions and cation-protein binding. To explore the cation binding behaviours to BSA and to explain potential differences between them, a comprehensive thermodynamic analysis using $\zeta$ potentials and isothermal titration calorimetry was performed. The results are summarised in the next section.

\subsection{Thermodynamics of cation-protein binding: zeta potential and ITC measurements}

In order to characterise the binding behaviour of cations to BSA, we measured BSA-salt sample series with increasing salt concentrations at different temperatures.

In Fig. 9 an exemplary temperature-dependent raw zeta potential data set of BSA in the presence of $\mathrm{HoCl}_{3}$ system is shown. Corresponding data sets were also obtained for BSA in the presence of $\mathrm{YCl}_{3}$ and $\mathrm{LaCl}_{3}$. For further analysis, the data were fitted using the following equation (see ESI $\dagger$ for derivation):

$$
Q=Q_{0}\left(1+\frac{c\left(Q_{0}-Q_{1}\right)\left(c_{1}-c_{0}\right)}{c\left(c_{0}\left(Q_{0}-Q_{1}\right)-c_{1} Q_{0}\right)+c_{0} c_{1} Q_{1}}\right)
$$

where $Q_{1}$ is the protein surface charge at the maximum salt concentration of $c_{1}=1 \mathrm{mM}$, and $c_{0}$ is the salt concentration at the point of zero charge. The initial protein charge $Q_{0}$ without added salt was fixed to $-9 e$, consistent with ref. 42 .

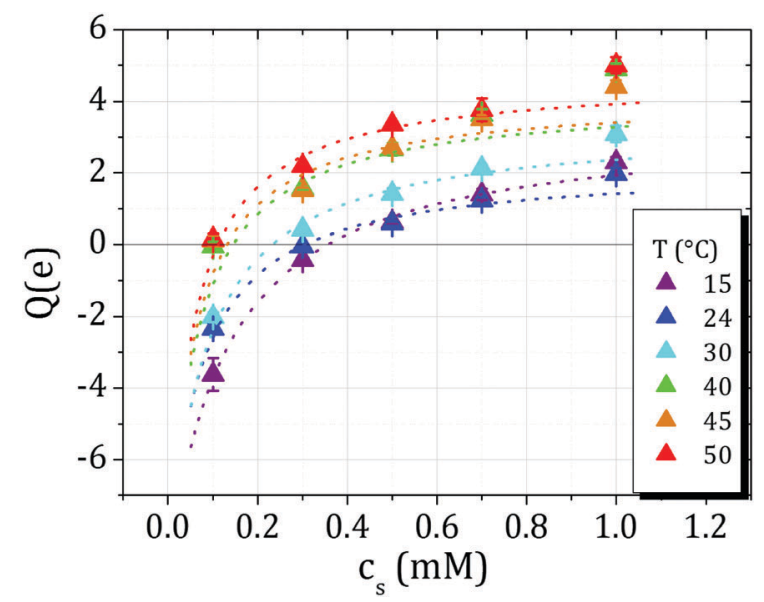

Fig. 9 Temperature-dependent $\zeta$ potential data of $1 \mathrm{mg} \mathrm{ml}^{-1}$ BSA with increasing $\mathrm{HoCl}_{3}$ concentrations. Each data point is an average of five measurements, error bars represent the standard deviation. The grey line indicates the point of zero charge $\left(c_{0}, Q=0\right)$. The zeta potential values obtained were converted to elementary charge values using the calculations described in the ESI. $\dagger$ The dashed lines represent fits to the data (eqn (8)). 


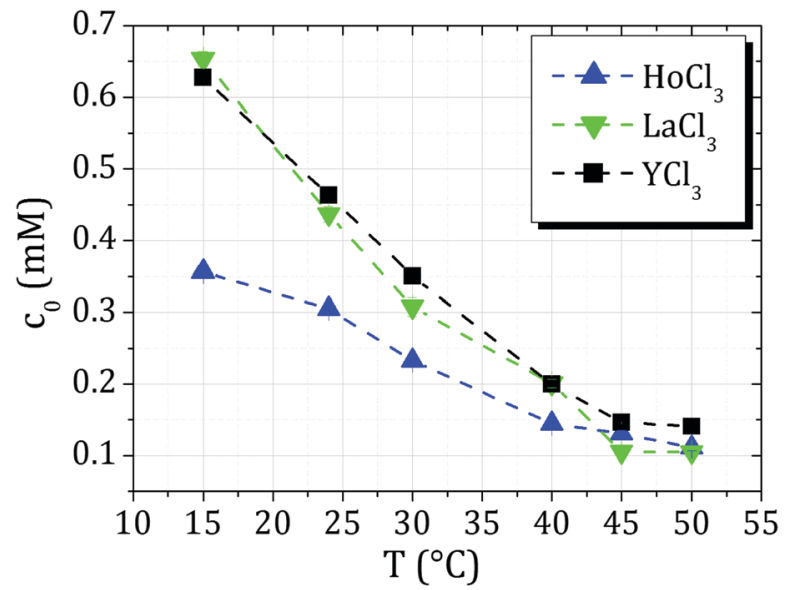

Fig. $10 C_{0}$ values for the $\mathrm{BSA}-\mathrm{YCl}_{3}, \mathrm{BSA}-\mathrm{LaCl}_{3}$ and $\mathrm{BSA}-\mathrm{HoCl}_{3}$ systems $\left(c_{\mathrm{p}}=1 \mathrm{mg} \mathrm{ml}^{-1}=15 \mu \mathrm{M}\right)$. The $c_{0}$ values were determined from fits (eqn (8)) to the raw $\zeta$ potential data as shown exemplarily in Fig. 9. Dashed lines are guides to the eye.

A first quantitative parameter obtained from the fit is $c_{0}$ as a function of temperature and type of salt. $c_{0}$ can be regarded as a measure for the cation-protein affinity. As can be seen from Fig. 10, $c_{0}$ decreases with temperature in every experimental system. This behaviour underlines the entropy-driven character of cation binding. ${ }^{42}$ Moreover, a strong difference between the BSA- $\mathrm{HoCl}_{3}$ system and the two other systems becomes obvious overall, less $\mathrm{Ho}^{3+}$ cations are needed to neutralise the BSA charge, indicating a stronger binding affinity of $\mathrm{Ho}^{3+}$ to BSA.

The average number of cations binding to the protein surface, $N$, can be calculated via the relation $N=\left(Q_{1}-Q_{0}\right) / 3$ with $Q_{0}=-9$ exploiting the fact that every cation has a charge of +3 . The respective values are shown in Fig. 11. As can be seen in Fig. 11, the average number again shows the sequence $\mathrm{Ho}^{3+}>\mathrm{Y}^{3+}>\mathrm{La}^{3+}$, with overall roughly $0.5-0.7$ more cations bound for $\mathrm{Ho}^{3+}$ compared to $\mathrm{La}^{3+}$. We remark that the exact choice for $Q_{0}$ is not essential for comparison between the cations, as the relative sequence in $N$ is robust against variations of $Q_{0}$.

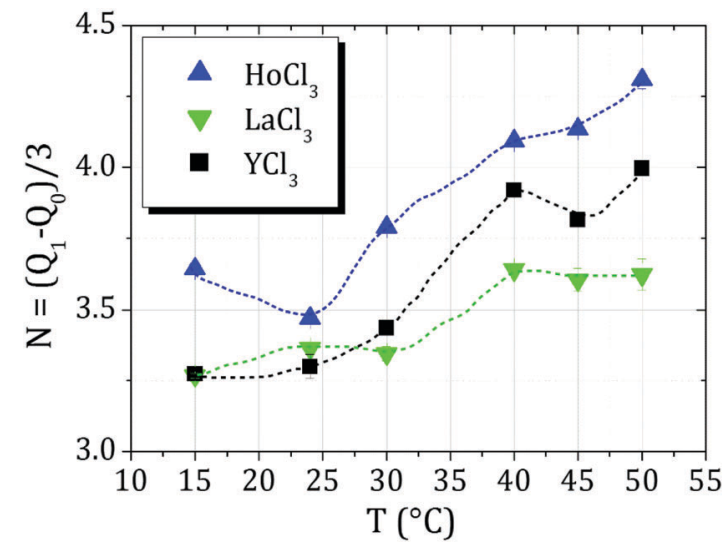

Fig. 11 Average number of cations, $N$, binding to BSA as calculated from $\zeta$ potential data as $\left(Q_{1}-Q_{0}\right) / 3, Q_{0}=-9$. Dashes lines are guides to the eye.

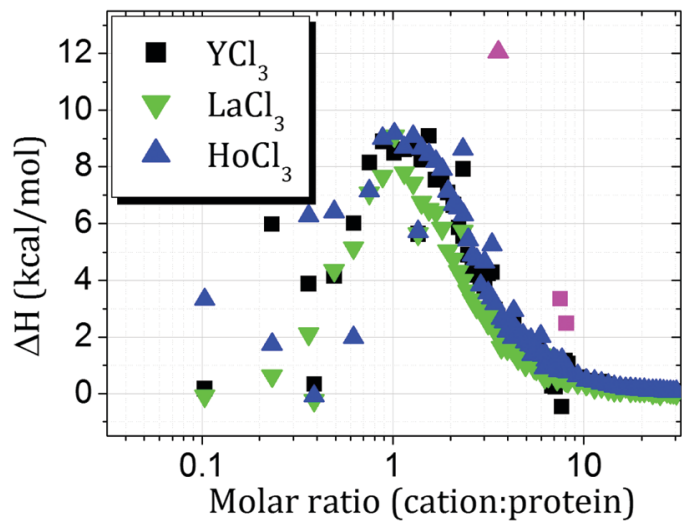

Fig. 12 ITC profiles of BSA titrated with $\mathrm{YCl}_{3}, \mathrm{HoCl}_{3}$ and $\mathrm{LaCl}_{3}$. Magenta data points were considered outliers and therefore excluded from the analysis. The data sets were merged from measurements performed with $3 \mathrm{mM}$ and $800 \mu \mathrm{M}$ salt solutions.

In order to thermodynamically quantify cation-protein binding, isothermal titration calorimetry (ITC) measurements were performed, as shown in Fig. 12. While the profiles for $\mathrm{HoCl}_{3}$ and $\mathrm{YCl}_{3}$ appear to be very similar, the systems with $\mathrm{LaCl}_{3}$ show a smaller enthalpic gain.

$\Delta H_{\text {bind }}$ was calculated by determining the integral of the curve until the respective molar ratios of zero charge $(=20.4$ for $\mathrm{HoCl}_{3}, 29.1$ for $\mathrm{LaCl}_{3}$ and 30.9 for $\mathrm{YCl}_{3}$ ) and divided by $Q_{0} /-\nu_{\mathrm{s}}{ }^{42}$ The obtained values read $10.6 \mathrm{kcal} \mathrm{mol}^{-1}$ for $\mathrm{HoCl}_{3}$, $10.4 \mathrm{kcal} \mathrm{mol}^{-1}$ for $\mathrm{YCl}_{3}$ and $7.8 \mathrm{kcal} \mathrm{mol}^{-1}$ for $\mathrm{LaCl}_{3}$, reiterating the observation that $\mathrm{LaCl}_{3}$ shows a smaller value, while $\mathrm{HoCl}_{3}$ and $\mathrm{YCl}_{3}$ appear similar. We note that due to batch-tobatch variations of $\mathrm{BSA},{ }^{70}$ potentially due to different content of co-ions remaining after the purification process, the absolute values of $\Delta H_{\text {bind }}$ should not be overinterpreted. Nevertheless, we argue that the values obtained here can be used for a semiquantitative characterisation of our systems, in particular when comparing the cation-BSA binding for different cations within the same BSA batch.

\section{Discussion}

Based on the characterisation of cation-protein association and cation-induced protein interactions for different trivalent cations, we now discuss the implications for a general understanding which physicochemical parameters determine the interactions between proteins and multivalent cations.

Cation radii are obvious parameters that can be seen as influencing the overall protein-ion interactions. In the present study, this is most clearly reflected in the $B_{2} / B_{2}^{\mathrm{HS}}$ values where stronger attractions go along with smaller cation radii. Similar findings were obtained by Schomäcker et $a l . .^{71}$ in a study showing a clearly linear dependence of human serum albumin and human blood serum affinity to Ln cations on cation radius. A publication by Smolka et al. ${ }^{72}$ furthermore provides a detailed discussion of the role of the cation radius regarding the affinity of $\mathrm{Ln}$ cations to $\alpha$-amylase, a system that is $\mathrm{Ca}^{2+}$-dependent 
under physiological conditions. According to the authors, the smallest cation is likely to experience the strongest attraction to the protein due to the fact that its charge is concentrated near its binding site on the protein. In the case of a strong cation binding site, this effect can compensate the high hydration free energy of the cation, which leads to an increased protein-cation affinity with decreasing cationic radius. ${ }^{72}$

While the relationship between cation radius and protein attraction strength appears straightforward in the case of the $B_{2} / B_{2}^{\mathrm{HS}}$ data, the $c_{0}$ calculations and ITC measurements indicate that the situation is more complex. This suggests that cationprotein binding energies (measured by ITC and zeta potentials) and cation-induced protein-protein bridging energies (measured by $T_{\text {trans }}$ and $\left.B_{2} / B_{2}^{\mathrm{HS}}\right)$ are not directly coupled. In particular, $c_{0}$, the salt concentration at the point of zero charge as a measure of cation-protein affinity, is rather similar for $\mathrm{Y}^{3+}$ and $\mathrm{La}^{3+}$, while the $c_{0}$ values of $\mathrm{Ho}^{3+}$ differ strongly. In contrast, the $B_{2} / B_{2}^{\mathrm{HS}}$ values of $\mathrm{Ho}^{3+}$ and $\mathrm{Y}^{3+}$ resemble each other, whereas those of $\mathrm{La}^{3+}$ are clearly higher. In the case of ITC, the $\Delta H_{\text {bind }}$ values are comparable for $\mathrm{Y}^{3+}$ and $\mathrm{Ho}^{3+}$ whereas they are lower for $\mathrm{La}^{3+}$, which indicates that no strong trends of cation-protein binding are seen in ITC. This may be caused by uncertainties of the experimental procedure and product purities. Since $c_{0}$ and $B_{2} / B_{2}^{\mathrm{HS}}$ measure cation-protein binding and cation-mediated protein-protein bridging, respectively, these findings appear to indicate that binding and bridging strengths can be different for the same cation.

A probable explanation for this difference is the different surface geometry in the case of a cation being bound to one protein as opposed to when it is bridging two proteins. As the binding appears to be driven by entropy of hydration water, ${ }^{42}$ the dehydration due to the first bond to one protein molecule might be very different from that of the second bond to another protein. This explanation also emphasises that cation radii are not the only parameters that need to be taken into account in order to rationalise the influence of different cations on protein phase behaviour. This assumption is corroborated by a study conducted by Gomez et $a l^{73}$ The authors investigated the abilities of lanthanide and $\mathrm{Y}^{3+}$ cations to restore the $\mathrm{Ca}^{2+}$ dependent biological activity of trypsinogen - another protein known to bind $\mathrm{Ca}^{2+}$ as well as lanthanide and $\mathrm{Y}^{3+}$ cations at aspartic acid residues - after depleting their trypsinogen system of $\mathrm{Ca}^{2+}$. At low lanthanide concentrations (around $10^{-4} \mathrm{M}$ ), the authors did not find a simple relationship between the cation radii and their efficiency in restoring the biological activity. Similarly, a non-monotonic relation between proteinlanthanide affinity and lanthanide radius has been found by Mulqueen et al. ${ }^{74}$

Gomez et al. $^{73}$ attribute their findings to potentially incomplete dehydration of different cations upon trypsinogen binding and to different amounts of water molecules bound to the protein-lanthanide complex. This aspect is very important to consider since our experimental system is known to be driven and strongly influenced by hydration effects. ${ }^{42,43}$ Gomez et al. ${ }^{73}$ furthermore observe that $\mathrm{Y}^{3+}$ has a protein-cation affinity not fitting into the expected trend based on the cationic radii of the lanthanides. Along with findings indicating that the strengths of different $\mathrm{Y}^{3+}$-ligand complexes vary strongly depending on the ligand chosen and can thus interfere with a straightforward integration of yttrium into trends of the lanthanide series ${ }^{75,76}$ this provides further evidence that parameters other than radius can play a role in the interactions between proteins and multivalent cations. These can e.g. include electron configuration $^{76,77}$ as well as cation polarisabilities and resulting dipoles. ${ }^{78}$

Previous work on the thermodynamic properties of lanthanides $^{79}$ reports higher entropic contributions for the complexation of $\mathrm{Ho}^{3+}$ to ethylenediaminetetraacetic acid (EDTA). While a protein is certainly more complex than the rather simple EDTA molecule, coordination of lanthanide cations in the case of BSA nevertheless also proceeds via carboxylic groups, making EDTA-lanthanide complex formation a reasonable reference point. Our previous work ${ }^{42}$ was strongly supported by earlier results obtained for lanthanide and $Y$ cations binding to amino acids in solution. ${ }^{80,81}$ Together with the zeta potential results which indicate a higher number of cations bound for $\mathrm{Ho}^{3+}$, this can help explain the stronger overall interprotein attraction induced by these cations.

The trypsinogen system investigated by Smolka et al. ${ }^{72}$ which we mentioned earlier is known to have two cation binding sites, whereas our system features several (around four) sites with varying local geometry. In addition to this, the cations used in the present work do not simply bind to BSA, but also bridge protein molecules and lead to an overall more complex phase behaviour of our system. ${ }^{42,45}$ The aspects mentioned by Gomez et al., ${ }^{73}$ especially cation and complex hydration, might thus have even more intricate effects on our systems. We suggest that these two aspects can thereby help explain the differences in BSA phase behaviour induced by different cations and the difference between $\mathrm{Y}^{3+}$ and $\mathrm{Ho}^{3+}$ in spite of the closeness of their cationic radii. This finding is consistent with the lower $T_{\text {trans }}$ values in the presence of $\mathrm{HoCl}_{3}$ as well as the larger LLPS areas obtained for BSA with $\mathrm{HoCl}_{3}$.

From a broader perspective on biological matter, it is interesting to compare the protein system to the well-studied example of DNA: analogously to the observations in our protein-cation systems, cation- ${ }^{82}$ and polymer- ${ }^{83}$ induced attraction between DNA strands can similarly stabilise and shift the melting temperature of DNA to higher values. An additional factor influencing the melting transition of DNA is its degree of hydration, ${ }^{84}$ which provides another conceptual link between phase transitions of DNA and proteins. The crucial aspect of hydration in our protein-cation systems will be discussed in more detail in the following.

Computational results on lanthanide cations in the absence of proteins confirm the importance of hydration effects and differences in cation hydration along the lanthanide series. Duvail et $a .^{85}$ performed an explicit polarisation molecular dynamics study on the exchange frequency (EF) of water molecules between the first hydration shell of lanthanide cations and bulk water. The EF shows a strongly nonmonotonic behaviour along the lanthanide series with the maximum EF being observed for $\mathrm{Tb}^{3+}$, a lanthanide cation 
located close to Ho in the periodic system. Additionally, the authors provide evidence for a change in both hydration water structure and coordination number along the lanthanide series, a result corroborating earlier findings by Habenschuss and Spedding $^{86-88}$ and studied in even more detail by Zhang et al. ${ }^{89}$ Persson et al. ${ }^{90}$ furthermore identified $\mathrm{Ho}^{3+}$ as the cation with the strongest change in hydration structure.

As a general caveat, it should be kept in mind that simulations and calculations for lanthanides and their properties encounter difficulties due to non-negligible relativistic effects ${ }^{89}$ caused by strong shielding of the nuclear charge,${ }^{91}$ a generally large number of electrons and incomplete $4 \mathrm{f}$ electron orbital occupation. ${ }^{89}$ Nevertheless, the above examples show that a large number of such studies exhibits good reproducibility and consistency. We assume that these findings can potentially help explain nonmonotonous effects that we observe in our experimental systems and that cannot be explained only by cation radii.

When discussing the effects the cations studied here have on protein phase behaviour, the classification of $\mathrm{Y}$ with respect to the lanthanide series is an important aspect to be mentioned. As apparent from the study by Gomez et al., ${ }^{73}$ this is not always straightforward. On the one hand, the chemical properties of Y are sufficiently close to the lanthanide series for it to be treated like a lanthanide; ${ }^{92}$ on the other hand, extensive studies classifying lanthanide and $\mathrm{Y}$ complexes with various ligands show that depending on the ligand, $\mathrm{Y}$ can behave similarly either to the heavy or the light lanthanides. ${ }^{75,76}$ This is consistent with our own observations that points of zero charge or enthalpies of Y-BSA binding do not always follow a trend that could be expected based on cation radii or position in the periodic system. Our results confirm that while BSA phase behaviour induced by $\mathrm{Y}^{3+}$ cations is sufficiently similar to that induced by lanthanides, it cannot always be expected to follow similar trends.

\section{Conclusions}

The experiments presented here offer an insight into the differences in protein phase behaviours - in particular liquidliquid phase separation (LLPS) - induced by the trivalent cations $\mathrm{Y}^{3+}, \mathrm{Ho}^{3+}$ and $\mathrm{La}^{3+}$. Whereas in the case of $\mathrm{La}^{3+}$ no phase separation is observed, $\mathrm{Ho}^{3+}$ leads to the formation of a dense phase which is potentially arrested. When $\mathrm{Y}^{3+}$ is used, the dense phase is more liquid-like. This difference in proteinprotein attractions induced by the different cations is reflected in the increase and decrease of the transition temperature $T_{\text {trans }}$ upon $\mathrm{LaCl}_{3}$ and $\mathrm{HoCl}_{3}$ addition to the BSA samples, respectively. In addition, the stronger interprotein attraction manifests itself in lower reduced second virial coefficient $B_{2} / B_{2}^{\mathrm{HS}}$ values as determined from SAXS experiments. The different cations used in this work can therefore tune thermal sensitivity of the samples. We emphasise that cation radius may not be the only parameter that should be considered when quantifying both cation-protein binding as well as cation-induced protein-protein interactions, and that hydration effects can be particularly important.
By carefully choosing multivalent cations, we are able to tune the phase transitions of aqueous BSA solutions. Our results thus provide a deeper understanding of thermodynamic fundamentals of colloidal and soft matter systems. Additionally, our findings are of relevance in the area of stimuli-responsive materials (e.g. for targeted drug delivery and release ${ }^{93}$ or water pollutant clearance ${ }^{94}$ ) where tuning the sensitivity to different environmental factors is of pivotal importance.

\section{Conflicts of interest}

There are no conflicts of interest to declare.

\section{Acknowledgements}

The authors gratefully acknowledge financial support by the Deutsche Forschungsgemeinschaft (DFG) and thank the ESRF for beamtime on beamline ID02. O. M. acknowledges a PhD fellowship by the Studienstiftung des Deutschen Volkes (German Academic Scholarship Foundation) and thanks the PSCM (Grenoble), Thilo Stehle and Nina Jaspert (Tübingen) for sharing their laboratory resources as well as Pinelopi Christodoulou for help with the ITC measurements. F. R.-R. acknowledges funding from the Knut and Alice Wallenberg Foundation (project grant KAW 2014.0052). The authors are grateful to Theyencheri Narayanan (ESRF, Grenoble), Leonardo Chiappisi (ILL, Grenoble), Stefano Da Vela, Martin Oettel and Roland Roth (Tübingen) and Michael Dolg (Cologne) for valuable discussions.

\section{References}

1 Y. Wang, A. Lomakin, T. Hideshima, J. P. Laubach, O. Ogun, P. G. Richardson, N. C. Munshi, K. C. Anderson and G. B. Benedek, Proc. Natl. Acad. Sci. U. S. A., 2012, 109, 13359-13361.

2 B. D. Mason, J. Z. van Enk, L. Zhang, R. L. Remmele, Jr. and J. Zhang, Biophys. J., 2010, 99, 3792-3800.

3 J. Berry, S. C. Weber, N. Vaidya, M. Haataja and C. P. Brangwynne, Proc. Natl. Acad. Sci. U. S. A., 2015, 112, E5237-E5245.

4 G. B. Benedek, Invest. Ophthalmol. Visual Sci., 1997, 38, 1911-1921.

5 F. Zhang, G. Zocher, A. Sauter, T. Stehle and F. Schreiber, J. Appl. Crystallogr., 2011, 44, 755-762.

6 E. Lomba and N. G. Almarza, J. Chem. Phys., 1994, 100, 8367-8372.

7 M. H. J. Hagen and D. Frenkel, J. Chem. Phys., 1994, 101, 4093-4097.

8 M. Muschol and F. Rosenberger, J. Chem. Phys., 1997, 107, 1953-1962.

9 V. J. Anderson and H. N. W. Lekkerkerker, Nature, 2002, 416, 811-815.

10 P. Papon, S. Schnur, J. Leblond and P. Meijer, The Physics of Phase Transitions: Concepts and Applications, Springer, Berlin Heidelberg, 2006. 
11 A. P. Gast, C. K. Hall and W. B. Russel, Faraday Discuss. Chem. Soc., 1983, 76, 189-201.

12 P. R. Sperry, H. B. Hopfenberg and N. L. Thomas, J. Colloid Interface Sci., 1981, 82, 62-76.

13 C. Ishimoto and T. Tanaka, Phys. Rev. Lett., 1977, 39, 474-477.

14 J. A. Thomson, P. Schurtenberger, G. M. Thurston and G. B. Benedek, Proc. Natl. Acad. Sci. U. S. A., 1987, 84, 7079-7083.

15 P. Schurtenberger, R. A. Chamberlin, G. M. Thurston, J. A. Thomson and G. B. Benedek, Phys. Rev. Lett., 1989, 63, 2064-2067.

16 M. L. Broide, C. R. Berland, J. Pande, O. O. Ogun and G. B. Benedek, Proc. Natl. Acad. Sci. U. S. A., 1991, 88, 5660-5664.

17 C. R. Berland, G. M. Thurston, M. Kondo, M. L. Broide, J. Pande, O. Ogun and G. B. Benedek, Proc. Natl. Acad. Sci. U. S. A., 1992, 89, 1214-1218.

18 P. L. San Biagio and M. U. Palma, Biophys. J., 1991, 60, 508-512.

19 O. Galkin, K. Chen, R. L. Nagel, R. E. Hirsch and P. G. Vekilov, Proc. Natl. Acad. Sci. U. S. A., 2002, 99, 8479-8483.

20 Q. Chen, P. G. Vekilov, R. L. Nagel and R. E. Hirsch, Biophys. J., 2004, 86, 1702-1712.

21 F. Cardinaux, T. Gibaud, A. Stradner and P. Schurtenberger, Phys. Rev. Lett., 2007, 99, 118301.

22 D. W. Urry, C.-H. Luan, T. M. Parker, D. C. Gowda, K. U. Prasad, M. C. Reid and A. Safavy, J. Am. Chem. Soc., 1991, 113, 4346-4348.

23 C. F. Lee, C. P. Brangwynne, J. Gharakani, A. A. Hyman and F. Jülicher, Phys. Rev. Lett., 2013, 1962-1966.

24 A. L. Lehninger, D. L. Nelson and M. M. Cox, Lehninger Principles of Biochemistry, W. H. Freeman, New York, 2005.

25 K. A. Majorek, P. J. Porebski, A. Dayal, M. D. Zimmerman, K. Jablonska, A. J. Stewart, M. Chruszcz and W. Minor, Mol. Immunol., 2012, 52, 174-182.

26 L. M. Gaetke and C. K. Chow, Toxicology, 2003, 189, 147-163.

27 A. Pałasz and P. Czekaj, Acta Biochim. Pol., 2000, 47, 1107-1114.

28 D. R. C. McLachlan, C. Bergeron, J. Smith, D. Boomer and S. L. Rifat, Neurology, 1996, 46, 401-405.

29 V. Rondeau, D. Commenges, H. Jacqmin-Gadda and J.-F. Dartigues, Am. J. Epidemiol., 2000, 152, 59-66.

30 A. Pol, T. R. M. Barends, A. Dietl, A. F. Khadem, J. Eygensteyn, M. S. M. Jetten and H. J. M. Op den Camp, Environ. Microbiol., 2014, 16, 255-264.

31 R. Murthy, R. Nunez, J. Szklaruk, W. Erwin, D. C. Madoff, S. Gupta, K. Ahrar, M. J. Wallace, A. Cohen, D. M. Coldwell, A. S. Kennedy and M. E. Hicks, Oncol. Interv., 2005, 2, S41-S55.

32 R. S. Stubbs, R. J. Cannan and A. W. Mitchell, J. Gastrointest. Surg., 2001, 5, 294-302.

33 A. D. Sherry, E. R. Birnbaum and D. W. Darnall, J. Biol. Chem., 1972, 70, 3489-3494.

34 S. R. Vallabhajosula, J. F. Harwig, J. K. Siemsen and W. Wolf, J. Nucl. Med., 1980, 21, 650-656.

35 P. Caravan, J. J. Ellison, T. J. McMurry and R. B. Lauffer, Chem. Rev., 1999, 99, 2293-2352.
36 E. Dadachova, S. Mirzaeh, S. V. Smith, F. F. Knapp Jr. and E. L. Hetherington, Appl. Radiat. Isot., 1997, 48, 477-481.

$37 \mathrm{~J} . \mathrm{Yu}, \mathrm{N}$. Jackson, X. Xu, Y. Morgenstern, Y. Kaufmann, M. Ruths, J. de Pablo and M. Tirrell, Science, 2018, 1438, 1434-1438.

38 F. Zhang, R. Roth, M. Wolf, F. Roosen-Runge, M. W. A. Skoda, R. M. J. Jacobs, M. Sztucki and F. Schreiber, Soft Matter, 2012, 8, 1313-1316.

39 F. Zhang, F. Roosen-Runge, A. Sauter, R. Roth, M. W. A. Skoda, R. Jacobs, M. Sztucki and F. Schreiber, Faraday Discuss., 2012, 159, 313-325.

40 F. Zhang, M. W. A. Skoda, R. M. J. Jacobs, S. Zorn, R. A. Martin, C. M. Martin, G. F. Clark, S. Weggler, A. Hildebrandt, O. Kohlbacher and F. Schreiber, Phys. Rev. Lett., 2008, 101, 148101.

41 F. Roosen-Runge, B. S. Heck, F. Zhang, O. Kohlbacher and F. Schreiber, J. Phys. Chem. B, 2013, 117, 5777-5787.

42 O. Matsarskaia, M. K. Braun, F. Roosen-Runge, M. Wolf, F. Zhang, R. Roth and F. Schreiber, J. Phys. Chem. B, 2016, 120, 7731-7736.

43 M. K. Braun, M. Wolf, O. Matsarskaia, S. Da Vela, F. RoosenRunge, M. Sztucki, R. Roth, F. Zhang and F. Schreiber, J. Phys. Chem. B, 2017, 121, 1731-1739.

44 S. Da Vela, M. K. Braun, A. Dörr, A. Greco, J. Möller, Z. Fu, F. Zhang and F. Schreiber, Soft Matter, 2016, 12, 9334-9341. 45 F. Roosen-Runge, F. Zhang, F. Schreiber and R. Roth, Sci. Rep., 2014, 4, 7016.

46 I. Koltover, K. Wagner and C. R. Safinya, Proc. Natl. Acad. Sci. U. S. A., 2000, 97, 14046-14051.

47 A. G. Cherstvy, A. A. Kornyshev and S. Leikin, J. Phys. Chem. $B, 2002,106,13362-13369$.

48 C. Pasquier, M. Vazdar, J. Forsman, P. Jungwirth and M. Lund, J. Phys. Chem. B, 2017, 121, 3000-3006.

49 E. Jordan, F. Roosen-Runge, S. Leibfarth, F. Zhang, M. Sztucki, A. Hildebrandt, O. Kohlbacher and F. Schreiber, J. Phys. Chem. B, 2014, 118, 11365-11374.

50 M. K. Braun, A. Sauter, O. Matsarskaia, M. Wolf, F. RoosenRunge, M. Sztucki, R. Roth, F. Zhang and F. Schreiber, in preparation.

51 C. A. Dreiss, K. S. Jack and A. P. Parker, J. Appl. Crystallogr., 2006, 39, 32-38.

52 P. Lindner and T. Zemb, Neutrons, X-rays, and Light: Scattering Methods Applied to Soft Condensed Matter, Elsevier, North-Holland, 2002.

53 G. Nägele, The Physics of Colloidal Soft Matter, Institute of Fundamental Technological Research, Warsaw, Poland, 2004.

54 J. Gunton, A. Shiryayev and D. Pagan, Protein Condensation: Kinetic Pathways to Crystallization and Disease, Cambridge University Press, 2007.

55 A. Guinier and G. Fournet, Small-angle scattering of X-rays, Wiley, New York, 1955, vol. 14.

56 W. Schärtl, Light scattering from polymer solutions and nanoparticle dispersions, Springer, 2007.

57 F. Bonneté and D. Vivarès, Acta Crystallogr., Sect. D: Biol. Crystallogr., 2002, 58, 1571-1575. 
58 N. Kern and D. Frenkel, J. Chem. Phys., 2003, 118, 9882-9889.

59 J. B. Hayter and J. Penfold, Mol. Phys., 1981, 42, 109-118.

60 J.-P. Hansen and J. B. Hayter, Mol. Phys., 1982, 46, 651-656.

61 R. J. Baxter, J. Chem. Phys., 1968, 49, 2770-2774.

62 S. V. G. Menon, C. Manohar and K. S. Rao, J. Chem. Phys., 1991, 95, 9186-9190.

63 M. G. Noro and D. Frenkel, J. Chem. Phys., 2000, 113, 2941-2944.

64 S. R. Kline, J. Appl. Crystallogr., 2006, 39, 895-900.

65 M. Wolf, F. Roosen-Runge, F. Zhang, R. Roth, M. W. Skoda, R. M. Jacobs, M. Sztucki and F. Schreiber, J. Mol. Liq., 2014, 200, 20-27.

66 P. D’Angelo, A. Zitolo, V. Migliorati, G. Chillemi, M. Duvail, P. Vitorge, S. Abadie and R. Spezia, Inorg. Chem., 2011, 50, 4572-4579.

67 R. D. Shannon, Acta Crystallogr., Sect. A: Cryst. Phys., Diffr., Theor. Gen. Crystallogr., 1976, 32, 751-767.

68 F. Zhang, F. Roosen-Runge, A. Sauter, M. Wolf, R. M. J. Jacobs and F. Schreiber, Pure Appl. Chem., 2014, 86, 191-202.

69 G. A. Vliegenthart and H. N. W. Lekkerkerker, J. Chem. Phys., 2000, 112, 5364-5369.

70 W. L. Hulse, J. Gray and R. T. Forbes, Int. J. Pharm., 2013, 453, 351-357.

71 K. Schomäcker, D. Mocker, R. Münze and G.-J. Beyer, Appl. Radiat. Isot., 1988, 39, 261-264.

72 G. E. Smolka, E. R. Birnbaum and D. W. Darnall, Biochemistry, 1971, 10, 4556-4561.

73 J. E. Gomez, E. R. Birnbaum and D. W. Darnall, Biochemistry, 1974, 13, 3745-3750.

74 P. Mulqueen, J. M. Tingey and W. D. W. Horrocks, Biochemistry, 1985, 24, 6639-6645.

75 T. Moeller and R. Ferrús, J. Inorg. Nucl. Chem., 1961, 20, 261-273.
76 T. Moeller, D. F. Martin, L. C. Thompson, R. Ferrus, G. R. Feistel and W. J. Randall, Chem. Rev., 1965, 65, 1-50.

77 E. Y. Permyakov, Metalloproteomics, Wiley, Hoboken, New Jersey, 2009.

78 C. Clavaguéra and J. P. Dognon, Chem. Phys., 2005, 311, 169-176.

79 G. R. Choppin, Pure Appl. Chem., 1971, 27, 23-41.

80 R. S. Sandhu, Monatsh. Chem., 1977, 108, 51-55.

81 F. M. Elzawawy, Monatsh. Chem., 1991, 122, 921-925.

82 A. G. Cherstvy and A. A. Kornyshev, J. Phys. Chem. B, 2005, 109, 13024-13029.

83 A. González, A. Wildes, M. Marty-Roda, S. Cuesta-López, E. Mossou, A. Studer, B. Demé, G. Moiroux, J. L. Garden, N. Theodorakopoulos and M. Peyrard, J. Phys. Chem. B, 2018, 122, 2504-2515.

84 F. Sebastiani, A. Pietrini, M. Longo, L. Comez, C. Petrillo, F. Sacchetti and A. Paciaroni, J. Phys. Chem. B, 2014, 118, 3785-3792.

85 M. Duvail, R. Spezia and P. Vitorge, Chem. Phys. Chem., 2008, 9, 693-696.

86 A. Habenschuss and F. H. Spedding, J. Chem. Phys., 1979, 70, 2797-2806.

87 A. Habenschuss and F. H. Spedding, J. Chem. Phys., 1979, 70, 3758-3763.

88 A. Habenschuss and F. H. Spedding, J. Chem. Phys., 1979, 73, 442-450.

89 J. Zhang, N. Heinz and M. Dolg, Inorg. Chem., 2014, 53, 7700-7708.

90 I. Persson, P. D’Angelo, S. De Panfilis, M. Sandström and L. Eriksson, Chem - Eur. J., 2008, 14, 3056-3066.

91 P. Pyykkö, Annu. Rev. Phys. Chem., 2012, 63, 45-64.

92 F. G. N. Cloke, Chem. Soc. Rev., 1993, 22, 17-24.

93 M. Constantin, eXPRESS Polym. Lett., 2011, 5, 839-848.

94 B. O. Okesola and D. K. Smith, Chem. Soc. Rev., 2016, 97, 219-243. 